Original Research

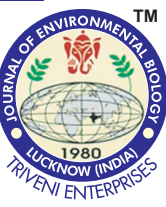

DOI : http://doi.org/10.22438/jeb/40/2/MRN-860

\title{
Production of low value and eco-friendly bio-preservatives from Lactobacillus plantarum grown on dairy whey
}

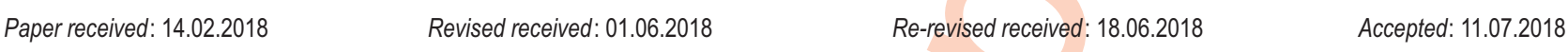

\section{Authors Info \\ B. Sowmiya and \\ S. Ramalingam* \\ Centre for Biotechnology, \\ Anna University, \\ Chennai- 600 025, India}

*Corresponding Author Email : ramabioprocess@annauniv.edu

\section{Edited by \\ Dr. J. Savitha}

Reviewed by

Dr. R.B. Raizada

Dr. K. Divakar

\section{Abstract}

Aim : The current study aimed to evaluate the potential of milk whey medium to produce low value biopreservatives.

Methodology : Lactobacillus plantarum NZ7100 was obtained from NIZO Food Research, Netherlands. To analyze optimal biomass, desired product and precursor production under whey/whey permeate supplemented with various yeast extract concentration $\left(0,5,10,15\right.$ and $\left.20 \mathrm{gl}^{-1}\right)$ and other economical media, batch fermentation was conducted and metabolites were analyzed using HPLC.

Results : The study showed that whey permeate containing $15 \mathrm{~g} \mathrm{I}^{-1}$ yeast extract supported maximum biomass formation of $1.7 \mathrm{gl}^{-1}$ with significant production of total lactic acid and D-lactic acid of about $9.78 \mathrm{gl}^{-1}$ and $4.41 \mathrm{~g} \mathrm{l}^{-1}$. The kinetic parameters evaluated with commercial growth medium such as MRS-glucose and MRS-lactose demonstrated relatively lesser growth and lactate yield in whey permeate medium than in MRS medium.

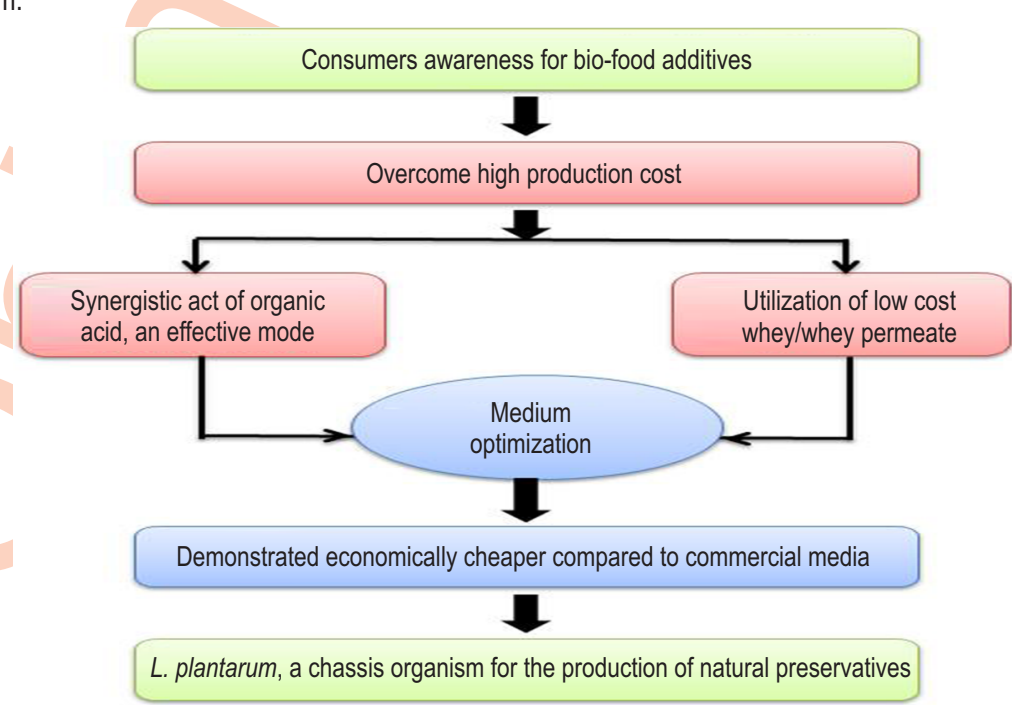

Interpretation : The study demonstrated the prospective of utilizing whey permeate medium to co-produce effective, eco- friendly, low cost natural preservatives using $L$. plantarum for usage in food and feed industry.

Key words: Growth kinetics, Lactic acid, Lactobacillus plantarum, Whey permeate, Yeast extract

How to cite: Sowmiya, B. and S. Ramalingam: Production of low value and eco-friendly bio-preservatives from Lactobacillus plantarum grown on dairy whey. J. Environ. Biol., 40, 211-216 (2019). 


\section{Introduction}

Consumer's awareness of chemical food additives and its related health issues has pulled down the usage of antibiotics in food and feed industry and driving the manufacturers to look for natural preservatives. In general, the cost of utilizing natural preservatives is comparatively higher than the effective chemical alternatives. In order to reduce the cost, it is essential to exploit the synergistic interactions of different natural preservatives and its direct formulation in the feed (Wemmenhove et al., 2016). Fatty acids are known to be antagonistic to most bacteria and yeast. Several studies have shown the effectiveness of utilizing lactic acid, acetic acid, propionic acid and their synergistic mixtures in culture media against the growth of undesirable harmfu microorganisms (Moon, 1983). Propionic acid, approved as "Generally Recognized as Safe" (GRAS) by the U.S. Food and Drug Administration, is the most effective antimicrobial and flavoring agent used in feed and food industry (Gonzalez-Garcia et al., 2017; Wee et al., 2006). Increasing demand has fueled the market of propionic acid globally, especially in emerging economies such as India, China, Brazil, etc. Thus, the future study has focused to synthesize propionic and lactic acid synergistically by engineering $L A B$, due to drawback associated with native propionate producers and favorable characteristics of the LAB (Gu et al., 1998; Smid et al., 2005). D-lactic acid formed by $L A B$ can be rerouted to produce propionic acid by engineering acrylate pathway. However, the main difficulty towards the largescale step-up are their low commercial value and raw material cost. Also, utilizing appropriate medium for the successful application of engineered LAB strain in preservatives is often necessary (Singh et al., 2016).

LAB are commonly cultured in MRS broth, but for largescale commercial applications its cost is prohibitive. To overcome this challenge, use of renewable feedstock is considered as a possible alternative for green chemical production. Among variously classified feedstock's, whey is considered as the most prominent raw material with respect to future applications. Milk whey/whey permeate is a cheap and abundant by-product of the dairy industry causing ecological stress. It is estimated that around $44-50 \%$ of whey produced worldwide are disposed in the environment (Greiter et al., 2002).

In India, the annual production of whey is estimated to be 5 million tons from dairy industry. Bioconversion of its high lactose content $(83.1 \%)$ to valuable products has been actively explored (Lin and Tanaka, 2006; Panesar et al., 2007). Co-production of propionic acid and lactic acid through lactic acid bacteria could gain commercial step up with whey lactose, as it can be formulated directly with animal feed by separating the cells, thus reducing the purification cost. Hence, the study was carried out using Lactobacillus plantarum due to its characteristic features such as acid tolerance, worldwide usage in food products, simple carbon metabolism and availability of efficient tools for genetic modification (Hassanzadazar et al., 2012; Rodríguez-Pazo et al., 2013; Pavan et al., 2000).
Thus, the present investigation was conducted as a prestudy for the development of strain for single step co-production of bio-preservatives (propionic acid and lactic acid) at a low cost fermentation process using whey/whey permeate. The specific objective was focused to examine the growth, total lactic acid and D-lactic acid formation rate (the key precursor in propionic acid synthesis) from the racemic mixture in $L$. plantarum using whey/whey permeate supplemented with different concentrations of yeast extract. Further, appropriate whey medium combination was compared with other relevant commercial media, such as MRS-glucose, MRS-lactose and MRS-glycerol, to highlight the appropriateness of whey medium in production of effective and low-value bio-preservatives.

\section{Materials and Methods}

Bacterial strain and growth conditions: Lactobacillus plantarum NZ7100 was obtained from NIZO Food Research, Netherlands. The study was conducted at the Centre for Biotechnology, Anna University, Chennai. The strain was propagated in MRS broth (HiMedia Laboratories, India) at $37^{\circ} \mathrm{C}$ for $24-48 \mathrm{hrs}$. The inoculum was obtained from cultures in the logarithmic phase of growth cultivated in $200 \mathrm{ml}$ MRS broth under anaerobic condition. The $\mathrm{pH}$ of broth was adjusted to 6.5 with $4 \mathrm{M} \mathrm{KOH}$.

Preparation of whey and whey permeate: Whey was made from milk treated with citric acid (Sharma et al., 2002). Whey permeates containing $3 \%$ protein content and $60 \%(\mathrm{w} / \mathrm{w})$ lactose was obtained from ACE International LLP, New Delhi. Protein precipitation was induced by heating the whey permeate at $90^{\circ} \mathrm{C}$ for $20 \mathrm{~min}$. Precipitated proteins were removed by centrifugation at $4,000 \mathrm{~g}$ for $15 \mathrm{~min}$ followed by ultrafiltration. Both whey and whey permeate were reconstituted to accomplish the preferred initial substrate concentration $\left(S_{0}\right)$ of $20 \mathrm{gl}^{-1}$ lactose. Further, yeast extract was supplemented with different concentrations of $5 \mathrm{~g} \mathrm{l}^{-1}$, $10 \mathrm{gl}^{-1}, 15 \mathrm{~g} \mathrm{l}^{-1}$ and $20 \mathrm{gl}^{-1}$. To study the effect of carbon source, whey and whey permeate was replaced by glucose or lactose in MRS. Salt solutions and sugars were sterilized separately at $121^{\circ} \mathrm{C}$ for $15 \mathrm{~min}$

Batch study: Batch bioreactor studies were carried out in a 2.4 I fermenter (KLF 2000-Bioengineering AG, Switzerland) with a working volume of $1.0 \mathrm{I}$. The $\mathrm{pH}$ was maintained at 6.5 by addition of $4 \mathrm{M} \mathrm{KOH}$. The temperature was maintained at $37^{\circ} \mathrm{C}$ and agitation speed at $200 \mathrm{rpm}$. The culture was grown under anaerobic condition by sparging sterile nitrogen gas and was continuously monitored using a DO probe. The seed culture was grown in MRS broth with $2 \%$ glucose, and about $10 \%$ (v/v) inoculum was used for batch fermentation.

Analytical procedures : For biomass estimation, the fermentation broth was centrifuged at $11,200 \times \mathrm{g}$ for $10 \mathrm{~min}$; the cell pellet obtained was suspended in $0.9 \% \mathrm{NaCl}$ solution and analyzed at $600 \mathrm{~nm}$. Glucose and lactose was analyzed using an Aminex column (HPX-87H, Bio-Rad, USA), maintained at $55^{\circ} \mathrm{C}$ using $5 \mathrm{mM} \mathrm{H}_{2} \mathrm{SO}_{4}$ as mobile phase at a flow rate of $0.4 \mathrm{ml} \mathrm{min}^{-1}$. D- 
lactate analysis was carried out at the Department of Biotechnology, Indian Institute of Technology, Chennai. It was estimated by using Chirex-penicillamine-D column (Phenomenex, USA) operated at $33^{\circ} \mathrm{C}$ with $1 \mathrm{mM} \mathrm{CuSO}_{4}$ as mobile phase and flow rate of $1 \mathrm{ml} \mathrm{min}^{-1}$.

\section{Results and Discussion}

Large-scale fermentative production of low-value bioproducts require process optimization besides strain improvement. Development of processes that utilize cheap raw materials at minimal cost have been under extensive studies (Taskila and Ojamo, 2013). Further optimization of such low-cost substrate for efficient supply of precursor molecules for enhanced product with supplementations is a critical process. One such prestudy was examined before initiating the chassis in exploiting Lactobacillus plantarum NZ7100 for bio-preservative coproduction. Several reports have shown the dependence of cell maintenance and metabolite production in lactobacilli with respect to the amount of nitrogen source in medium (Hayek and
Ibrahim, 2013). Supplementation of yeast extract is one of the key factors in fermentation (Laitila et al., 2004). However, the high cost of yeast extract limits its usage in large scale production; this necessitates optimizing yeast extract concentration in medium to achieve high productivity.

Impact on growth behavior of Lactobacillus plantarum NZ7100 for batch experiments carried out in whey permeate medium supplemented with different initial yeast extract concentration $\left(0,5,10,15\right.$ and $\left.20 \mathrm{~g} \mathrm{l}^{-1}\right)$ is shown in Fig. $1 \mathrm{~A}$. Increasing levels of yeast extract significantly influenced the growth of cells. Exponential growth was observed proportional to yeast extract concentration, whereas in medium without yeast extract, cell growth remained retarded. In $5 \mathrm{gl}^{-1}$ yeast extract, the exponential growth of $14 \mathrm{hrs}$ was followed by a gradual decline in growth. This transition was attributed to the depletion of nitrogen source present at sub-optimal level in the medium. However, medium containing $10 \mathrm{~g} \mathrm{l}^{-1}$ yeast extract exhibited gradual increase in cell mass but resulted in a longer growth period of 22 hrs. While addition of $15 \mathrm{~g} \mathrm{l}^{-1}$ yeast extract besides reducing the
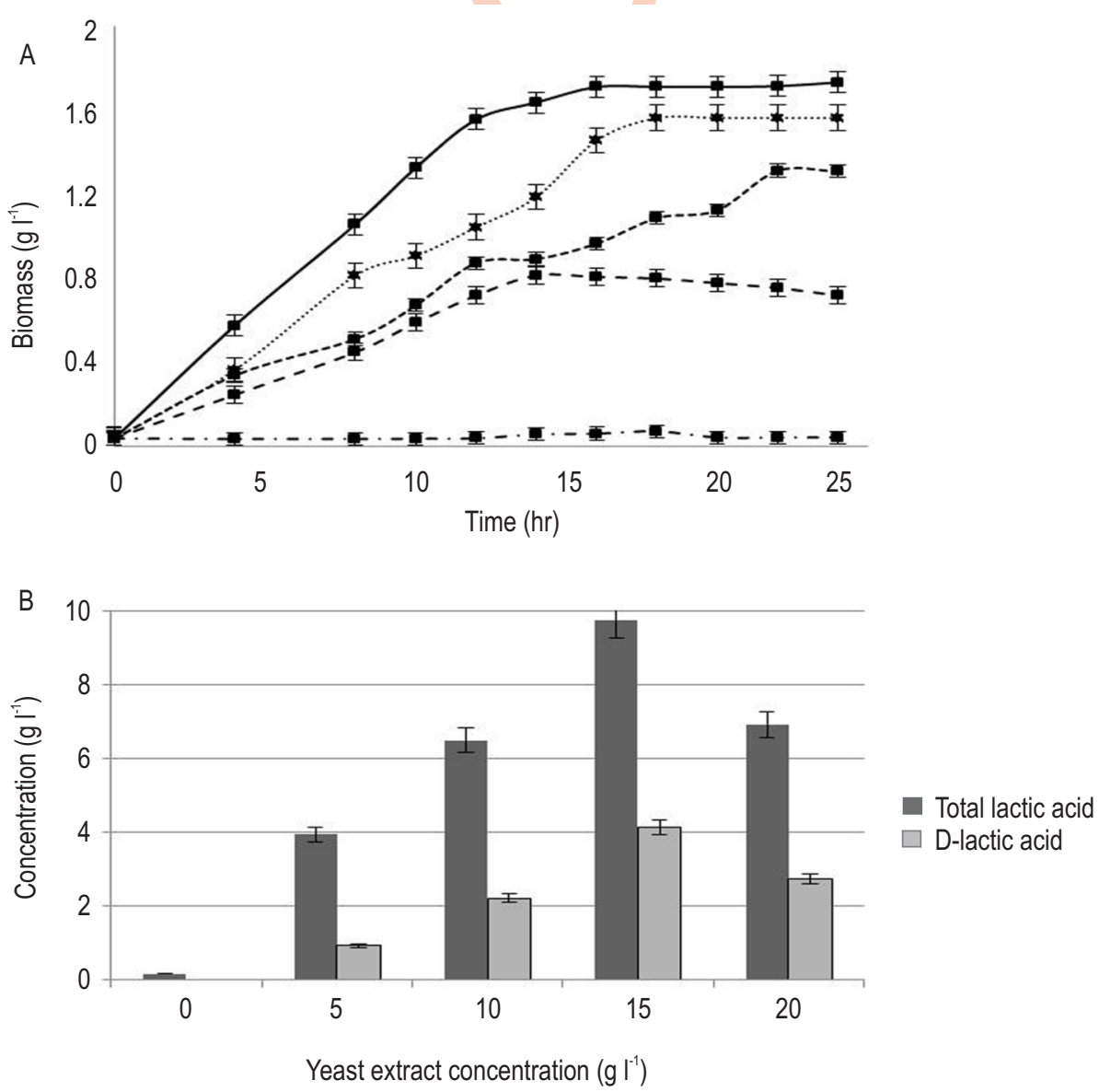

Fig.1: Effect of yeast extract concentrations on biomass formation (A), total lactate and D-lactate production (B) in whey permeate. 

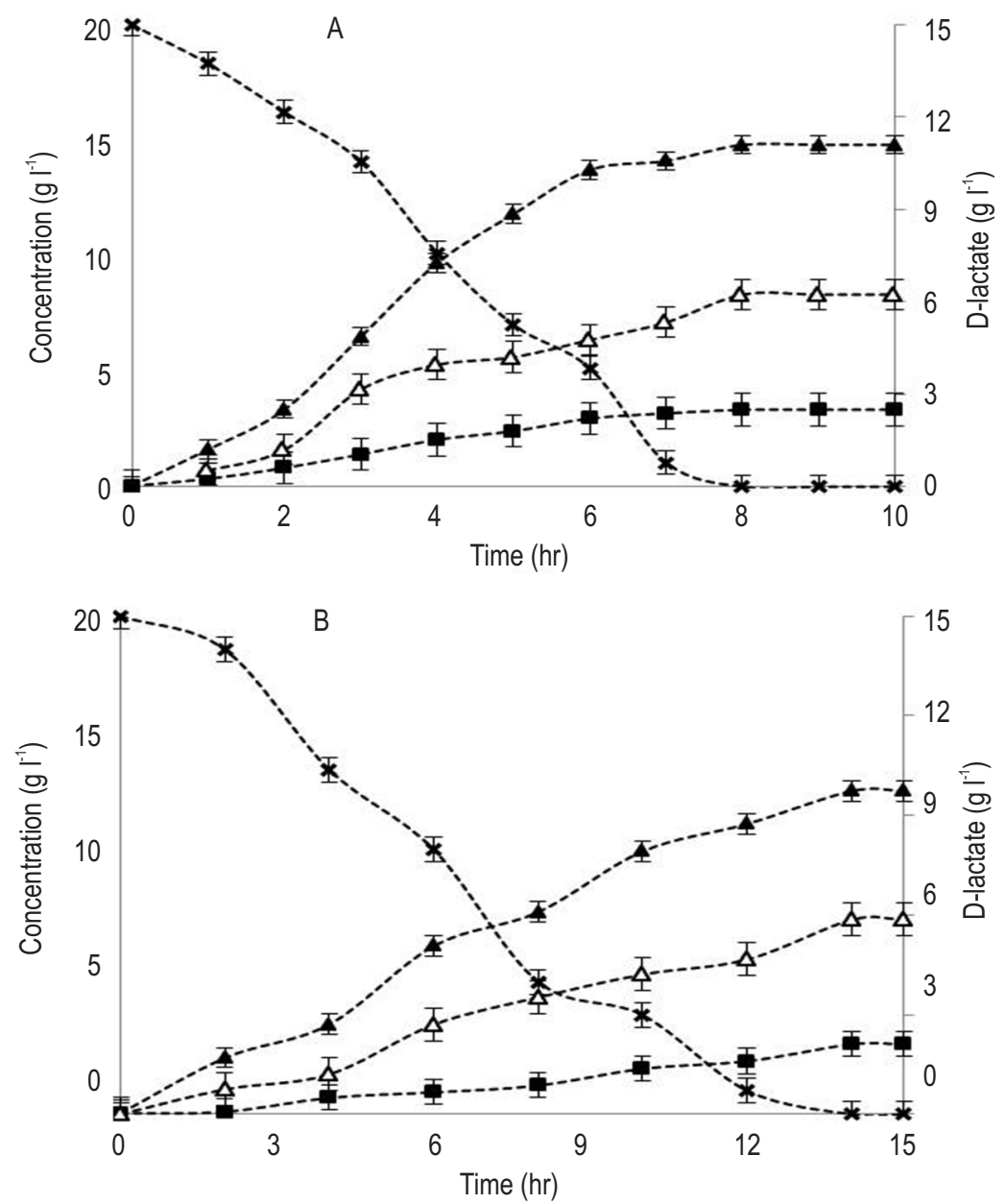

Fig. 2 : Fermentation profile of $L$. plantarum NZ 7100 grown in MRS medium supplemented with glucose (A) and lactose (B). Time course of glucose consumption $(\mathbf{x})$, biomass $(\boldsymbol{\square})$, total lactate $(\boldsymbol{\Delta})$ and D-lactate $(\triangle)$.

fermentation time $(14 \mathrm{hr})$, promoted biomass concentration to reach its maximum. Beyond $15 \mathrm{~g} \mathrm{l}^{-1}$, decline in cell concentration was noticed, as a result of stimulated toxic effects reported at higher yeast extract concentration. Similar reports by Benaissa et al. (2016) have shown significant increase in growth performance of Lactobacillus in whey medium supplemented with yeast extract and/or tomato juice.

Relatively, lactose utilization in case of fermentation conducted with $5 \mathrm{~g} \mathrm{l}^{-1}$ yeast extract concentrations initially followed similar profile as that of $10 \mathrm{gl}^{-1}$ and $20 \mathrm{~g} \mathrm{I}^{-1}$ yeast extract, however, after $10 \mathrm{hr}$ the consumption rate gradually decreased due to reduced growth. Khalil et al. (2014) described the influence of different yeast extract concentrations on residual lactose concentration. However in fermentations with 10, 15 and $20 \mathrm{~g} \mathrm{l}^{-1}$ yeast concentration, lactose was completely utilized except the difference in overall fermentation time. Fermentation time has dramatic reflection on the cost of fermentation process, and hence on the economics of the desired product production. As compared to the biomass generation, the rate of lactic acid formation also increased with yeast extract concentration and reached its optimum with yeast extract concentration of $15 \mathrm{~g} \mathrm{I}^{-1}$ (Fig. 1B). At $14 \mathrm{hr}$, lactose was completely utilized and attained the highest total lactic acid titre of $9.78 \mathrm{~g} \mathrm{l}^{-1}$ and D-lactic acid concentration of $4.41 \mathrm{gl}^{-1}$. In case of $10 \mathrm{~g} \mathrm{I}^{-1}$ yeast extract, the total lactose was utilized in about $22 \mathrm{hr}$ with production of $6.5 \mathrm{~g} \mathrm{l}^{-1}$ lactic acid. With $20 \mathrm{~g} \mathrm{l}^{-1}$ yeast extract, the fermentation continued up to $18 \mathrm{hr}$ and reached the maximum lactic acid concentration of $7 \mathrm{gl}^{-1}$; whereas lactic acid production was very low or absent when no supplement was added.

The above inconsistency in growth and lactic acid production was attributed to sub-optimal concentration of nitrogen source provided. The overall productivity obtained with $15 \mathrm{gl}^{-1}$ and $20 \mathrm{gl}^{-1}$ yeast extract was $0.61 \mathrm{gl}^{-1} \mathrm{~h}^{-1}\left(0.27 \mathrm{gl}^{-1} \mathrm{hr}^{-1} \mathrm{D}\right.$ lactate) and $0.38 \mathrm{~g} \mathrm{l}^{-1} \mathrm{hr}^{-1}$, whereas 5 and $10 \mathrm{~g} \mathrm{l}^{-1}$ yeast extract 
Table 1 : Kinetic growth parameters of $L$. plantarum NZ7100 strain in modified MRS media with different carbon source and whey permeate

\begin{tabular}{llllll}
\hline Medium & \multicolumn{5}{c}{ Kinetic parameters } \\
\cline { 2 - 6 } & $\boldsymbol{\mu}_{\max }\left(\mathbf{h r}^{-1}\right)$ & Yx/s $\left.\mathbf{~ g ~ g ~}^{-1}\right)$ & Yp/s $\left(\mathbf{g ~ g ~}^{-1}\right)$ & Total lactate $\left(\mathbf{g ~ l}^{-1}\right)$ & D-lactate $\left(\mathbf{g ~ l}^{-1}\right)$ \\
\hline MRS-Glucose & $0.64 \pm 0.001$ & $0.17 \pm 0.003$ & $0.74 \pm 0.001$ & $14.81 \pm 0.011$ & $6.24 \pm 0.012$ \\
MRS-Lactose & $0.58 \pm 0.009$ & $0.14 \pm 0.003$ & $0.65 \pm 0.001$ & $13.98 \pm 0.015$ & $5.86 \pm 0.011$ \\
WP/YE (1.5\%) & $0.51 \pm 0.007$ & $0.09 \pm 0.016$ & $0.48 \pm 0.003$ & $9.78 \pm 0.033$ & $4.14 \pm 0.037$ \\
\hline
\end{tabular}

decreased the productivity to 0.19 and $0.32 \mathrm{gl}^{-1} \mathrm{hr}^{-1}$, respectively. Sreenath et al. (2001) reported similar productivity range $\left(0.64 \mathrm{~g} \mathrm{l}^{-1}\right.$ $\left.\mathrm{hr}^{-1}\right)$ using alfalfa fibers as substrate. Moreover, concerning substrate utilization, strain growth and product production, whey permeate was recognized to be efficient than pure whey (data not shown), therefore growth in whey permeate was selected for further analysis. From the above study, it was found that the optimal growth and lactate formation occurred with the combination of whey permeate supplemented with $15 \mathrm{~g} \mathrm{I}^{-1}$ yeast extract (WP/YE). Similar results was reported by Li et al. (2011) using four point yeast extract supplementation in order to maximize biomass and polyvinyl alcohol-degrading enzymes production. Klotz et al. (2017) reported the positive effect of varying yeast extract concentration on the productivity of $D$ - lactic acid. In general, studies have shown that utilizing agriculture raw materials instead of yeast extract predominantly resulted in lower growth and productivity (Lu et al., 2009). Therefore, it is necessary to negotiate the cost for efficient product production. Reports have also demonstrated the significance of fermentation medium optimization, especially precursor biosynthesis for high end product synthesis (Singh et al., 2016).

Consequently, the results obtained from the comparative study demonstrated significant growth and high productivity $(\varphi)$ in culture media supplemented with glucose (Fig. 2A) and lactose (Fig. 2B), but in the presence of glycerol almost no growth was detected. The biomass formed reached its maximum within $8 \mathrm{hr}$ during glucose fermentation whereas an extended fermentation period of $14 \mathrm{hr}$ was observed with lactose. The yield coefficients corresponding to product formation (Yp/s) was elevated in the presence of glucose followed by lactose (Table 1). The major product of carbohydrate conversion was lactic acid, accompanied by a negligible amount of acetic acid. The highest $\mathrm{D}$-lactate yield $\left(0.31 \mathrm{~g} \mathrm{~g}^{-1}\right)$ was observed in the presence of glucose, whereas medium supplemented with lactose and WP/YE resulted in about 0.29 and $0.2 \mathrm{~g} \mathrm{~g}^{-1}$ of D-lactate. The yield obtained using WP/YE were found to be lower compared to the MRS-Glu/Lac medium. It was anticipated due to the inhibitory potential of protein components present in trace amount in whey permeate that might have possibly lowered the growth, and therefore the metabolic response for product production (Kassem, 2015). Nevertheless, the fermentation process utilizing whey permeate showed relatively good lactic acid and D-lactic acid supply besides growth, thus acting as a promising medium for bio-preservative co-production. Similarly, Ray et al. (2009) showed the application of agri-waste in lactic acid production by optimizing conditions required for maximum substrate conversion. Chookietwattana (2014) reported lactic acid yield of $0.17 \mathrm{~g} \mathrm{~g}^{-1}$ from the fermentation of cassava starch by Lactobacillus plantarum.

To conclude, in a process to produce eco-friendly bioadditives, process cost should be considered to that of productivity. The present study has paved a way for dual advantage: cheap process development which can be commercialized for the benefit of biotechnology industry and cutting-edge technology for value addition of dairy waste, thereby reducing the environmental burden.

\section{Acknowledgment}

Authors are thankful to the University Grants Commission for providing Basic Science Research (BSR) fellowship.

\section{References}

Benaissa, M., H. Zadi-Karam and N.E. Karam: Development of a sweet whey-based medium for culture of Lactobacillus. Afr. J. Biotechnol., 16, 1630-1637 (2017).

Chookietwattana, K.: Lactic acid production from simultaneous saccharification and fermentation of cassava starch by Lactobacillus plantarum MSUL 903. APCBEE Procedia, 8,156160 (2014).

Gonzalez-Garcia, R.A., T. McCubbin, L. Navone, C. Stowers, L.K. Nielsen and $\mathrm{E}$. Marcellin: Microbial propionic acid production. Fermentation, 3, 1-20 (2017).

Greiter, M., S. Novalin, M. Wendland, K.D. Kulbe and J. Fischer: Desalination of whey by electrodialysis and ion exchange resins: Analysis of both processes with regard to sustainability by calculating their cumulative energy demand. J. Memb. Sci., 210, 91-102 (2002)

Gu, Z., B.A. Glatz and C.E. Glatz: Propionic acid production by extractive fermentation. I. Solvent considerations. Biotechnol. Bioeng., 57, 454-61 (1998).

Hassanzadazar, H., A. Ehsani, K. Mardani and J. Hesari: Investigation of antibacterial, acid and bile tolerance properties of lactobacilli isolated from Koozeh cheese. Vet. Res. Forum, 3, 181-185 (2012).

Hayek, S.A. and S.A. Ibrahim: Current limitations and challenges with lactic acid bacteria: Areview. Food Nutr. Sci., 4, 73-87 (2013).

Kassem, J. M.: Future challenges of whey proteins. Int. J. Dairy Sci., 10, 139-159(2015)

Khalil, K.A., S. Mustafa, R. Mohammad, A.B. Ariff, Y. Shaari, Y.A. Manap, S.A. Ahmad and F.A. Dahalan: Optimization of milk-based medium for efficient cultivation of Bifidobacterium pseudocatenulatum G4 using face-centered central composite-response surface methodology. Biomed. Res. Int., 2014, 1-11 (2014).

Klotz, S., A. Kuenz and U. Prüße: Nutritional requirements and the impact 
of yeast extract on the D-lactic acid production by Sporolactobacillus inulinus. Green Chem., 19, 4633-4641 (2017).

Laitila, A., M. Saarela, L. Kirk, M. Siika-aho, A. Haikara, T. MattilaSandholm and I. Virkajärvi: Malt sprout extract medium for cultivation of Lactobacillus plantarum protective cultures. Lett. Appl. Microbiol., 39, 336-340 (2004).

Li, M., X. Liao, D. Zhang, G. Du and J. Chen: Yeast extract promotes cell growth and induces production of polyvinyl alcohol-degrading enzymes. Enzyme Res., 2011, 1-8 (2011).

Lin, Y. and S. Tanaka: Ethanol fermentation from biomass resources: Current state and prospects. Appl. Microbiol. Biotechnol., 69, 627642 (2006).

Lu, Z., M. Lu, F. He and L. Yu: An economical approach for D-lactic acid production utilizing unpolished rice from aging paddy as major nutrient source. Bioresour. Technol., 100, 2026-2031 (2009).

Moon, N.J.: Inhibition of the growth of acid tolerant yeasts by acetate, lactate and propionate and their synergistic mixtures. J. Appl. Bacteriol., 55, 453-460 (1983).

Panesar, P.S., J.F. Kennedy, D.N. Gandhi and K. Bunko: Bioutilisation of whey for lactic acid production. Food Chem., 105, 1-14 (2007).

Pavan, S., P. Hols, J. Delcour, M.C. Geoffroy, C. Grangette, M. Kleerebezem and A. Mercenier: Adaptation of the nisin-controlled expression system in Lactobacillus plantarum: A tool to study in vivo biological effects. Appl. Environ. Microbiol., 66, 4427-4432 (2000).

Ray, R.C., P. Sharma and S.H. Panda: Lactic acid production from cassava fibrous residue using Lactobacillus plantarum MTCC 1407. J. Environ. Biol., 30, 847-852 (2009).

Rodríguez-Pazo, N., L. Vázquez-Araújo, N. Pérez-Rodríguez, S. CortésDiéguez and J.M. Domínguez: Cell-free supernatants obtained from fermentation of cheese whey hydrolyzates and phenylpyruvic acid by Lactobacillus plantarum as a source of antimicrobial compounds, bacteriocins, and natural aromas. Appl. Biochem. Biotechnol., 171, 1042-1060 (2013).

Sharma, R.B., M. Kumar, V. Pathak and M. Kumar: Effect of different seasons on crossbred cow milk composition and paneer yield in subhimalayan region. Asian-Australas J. Anim. Sci., 15, 528-530 (2002).

Singh, V., S. Haque, R. Niwas, A. Srivastava, M. Pasupuleti and C.K.M. Tripathi: Strategies for fermentation medium optimization: An indepth review. Front Microbiol., 7, 1-16 (2016)

Smid, E.J., F.J.V. Enckevort, A. Wegkamp, J. Boekhorst, D. Molenaar, J. Hugenholtz, R.J. Siezen and B. Teusink: Metabolic models for rational improvement of lactic acid bacteria as cell factories. $\mathrm{J}$. Appl. Microbiol., 98, 1326-1331 (2005).

Sreenatha, H.K., A.B. Moldes, R.G. Koegel and R.J. Strauba: Lactic acid production by simultaneous saccharification and fermentation of alfalfa fiber. J. Biosci. Bioeng., 92, 518-523 (2001).

Taskila, S. and H. Ojamo: The current status and future expectations in industrial production of lactic acid by lactic acid bacteria. In: Lactic Acid Bacteria - R \& D for Food, Health and Livestock Purposes (Ed.: M. Kongo). In Tech Publishers, pp. 615-632 (2013).

Wee, Y.J., J.N. Kim and H.W. Ryu: Biotechnological production of lactic acid and its recent applications. Food Technol. Biotechnol., 44, 163-172(2006).

Wemmenhove, E., H.J. van Valenberg, M.H. Zwietering, T.C. van Hooijdonk and M.H. Wells-Bennik: Minimal inhibitory concentrations of undissociated lactic, acetic, citric and propionic acid for Listeria monocytogenes under conditions relevant to cheese. Food Microbiol., 58, 63-67 (2016). 